\title{
A Novel Core-Shell Structured Nickel-rich Layered Cathode Material for High- Energy Lithium-Ion Batteries
}

\author{
Hui Tong, ${ }^{1}$ Qijie Zhou, ${ }^{1}$ Bao Zhang, ${ }^{1}$ Xu Wang, ${ }^{1}$ Yingying Yao, ${ }^{1}$ Zhiying Ding, ${ }^{2}$ Hezhang Chen, ${ }^{1,3}$ Junchao Zheng and Wanjing Yu ${ }^{1 *}$
}

For enhancing the electrochemical properties of lithium transition-metal oxide, a novel core-shell structured cathode material $\mathrm{LiNi}_{0.75} \mathrm{Co}_{0.12} \mathrm{Mn}_{0.13} \mathrm{O}_{2} @ \mathrm{~V}_{2} \mathrm{O}_{5}$ was designed and synthesized. The precursor of the material was made of metal hydroxide in the interior and metal carbonate in the exterior, and with full concentration gradient structure. In this cathode material, the core was the high-Ni material, and the shell was the high-Mn material. The sphere material was coated and penetrated by $\mathrm{V}_{2} \mathrm{O}_{5}$ due to the existence of pores. Furthermore, the material was also doped by vanadium element. These were investigated and confirmed by X-ray diffraction, Focused Ion beam, EDS, TEM, etc. The 3 wt $\%$ $\mathrm{V}_{2} \mathrm{O}_{5}$-coated sample exhibited a remarkable cycling performance, with capacity retention of $86.5 \%$ at the current rate of $1 \mathrm{C}$ after 100 cycles. Besides, the rate capability of the $\mathrm{V}_{2} \mathrm{O}_{5}$-coated sample was obviously enhanced at high rates $(2,5$ and $10 \mathrm{C})$. The interfacial charge transfer resistance of the material after cycling was obviously decreased by $\mathrm{V}_{2} \mathrm{O}_{5}$ coating. The cyclic voltammetry analysis showed that the interfacial polarization of the material was inhibited due to $\mathrm{V}_{2} \mathrm{O}_{5}$ coating.

Keywords: Lithium transition-metal oxide; Cathode material; Core-shell structure; Full concentration gradient; Lithium-ion batteries

Received 21 February 2019, Accepted 26 March 2019

DOI: $10.30919 / \mathrm{es} 8 \mathrm{~d} 502$

\section{Introduction}

Recently, people are seeking for the alternatives to fossil fuels due to the dramatically serious problem of environmental pollution in the world. $^{1-5}$ Lithium ion batteries (LIBs) are widely applied in electric vehicle battery series and energy storage systems due to excellent energy density, performance and long life. ${ }^{6-8}$ In LIB system, the cathode material restricts the overall performance of the batteries. ${ }^{7,9}$ The cathode materials, represented by $\mathrm{LiCoO}_{2}, \mathrm{LiNi}_{13} \mathrm{Co}_{13} \mathrm{Mn}_{13} \mathrm{O}_{2}, \mathrm{LiMn}_{2} \mathrm{O}_{4}$ and $\mathrm{LiFePO}_{4}$, are successfully applied to batch production of industrialization. In order to further improve the energy density of the battery, the high nickel cathode material for LIBs is developed. 10, ${ }^{11}$ However, severe capacity attenuation of high nickel cathode materials hinders further application, especially in high rate and long period of cycling. Such limitation is caused by the formation of $\mathrm{Ni}^{4+}$ ions, ${ }^{12}$ which present a strong oxidizing property and react with the electrolyte. ${ }^{13,14}$

Y. K. Sun, et al. synthesized core-shell spherical material $\mathrm{Li}\left(\mathrm{Ni}_{0.8} \mathrm{Co}_{0.1} \mathrm{Mn}_{0.1}\right)_{0.8}\left(\mathrm{Ni}_{0.5} \mathrm{Mn}_{0.5}\right)_{0.2} \mathrm{O}_{2}$ with high-nickel core and low-nickel shell by co-precipitation method. ${ }^{15}$ Shell material $\mathrm{LiNi}_{0.5} \mathrm{Mn}_{0.5} \mathrm{O}_{2}$ showed a lower capacity compared with that of the core material. But, the shell material could enhance the cycling stability of the core-shell material. Although the core-shell structure can improve the cycling stability and thermal stability of the material, the junction between the core and the

${ }^{\prime}$ School of Metallurgy and Environment, Central South University, Changsha 410083, China

${ }^{2}$ School of Chemistry and Chemical Engineering, Central South University, Changsha 410083, China

${ }^{3}$ School of Chemistry and Chemical Engineering, Hunan University of Science and Technology, Xiangtan 411201, China

*E-mail:yuwj2005@163.com shell were separated after a long period of cycling. So, the cycling stability of the core-shell structure material cannot be guaranteed. Subsequently, a new core-shell structural material with concentration gradient was reported in 2009, ${ }^{16-18}$ and a full concentration gradient (FCG) material was reported in 2012. ${ }^{19}{ }^{20}$ The electrochemical properties of the two kinds of materials were both improved. However, the transition metals still could be dissolved and reacted with the electrolyte. Furthermore, as the promising energy materials, the rate performance should be further improved. At present, there are several routes to solve the problems and improve the properties of the electrode materials: nano-treatment, morphological control, surface modification and composition optimization, etc. ${ }^{21-26}$ Surface coating is an effective way to slow down the side reactions, inhibit the dissolution of the transition metal ions, and enhance the cycling performance. Some coating materials are usually used, such as $\mathrm{Al}_{2} \mathrm{O}_{3}^{27}, \mathrm{TiO}_{2}^{28}, \mathrm{AlPO}_{4}^{29}, \mathrm{AlF}_{3}^{30}, \mathrm{ZrO}_{2}^{31}$, and $\mathrm{LiAlO}_{2}^{32}$, etc. Vanadium pentoxide $\left(\mathrm{V}_{2} \mathrm{O}_{5}\right)$ is not only considered as one of the high capacity cathode materials for $\mathrm{LIBs}^{33}$ but also a coating material with good performance. ${ }^{34,35}$ In addition, $\mathrm{V}_{2} \mathrm{O}_{5}$ possesses a relatively higher lithium-ion diffusivity than most metal oxides, metal phosphates and metal fluorides, as well as electrical conductivity. ${ }^{36}$

In this work, a novel FCG material $\mathrm{LiNi}_{0.75} \mathrm{Co}_{0.12} \mathrm{Mn}_{0.13} \mathrm{O}_{2}$ with coreshell structure was designed and prepared. The precursor was composed of metal hydroxide in the core and metal carbonate in the shell. The core-shell structured FCG $\mathrm{LiNi}_{0.75} \mathrm{Co}_{0.12} \mathrm{Mn}_{0.13} \mathrm{O}_{2}$ sphere material was prepared through using this special precursor. The shell material contained higher concentration of $\mathrm{Mn}$ and lower concentration of $\mathrm{Ni}$ compared with those of the FCG material prepared by metal hydroxide precursor, which is beneficial for inhibiting the side reactions and improving the electrochemical performance. The $\mathrm{LiNi}_{0.75} \mathrm{Co}_{0.12} \mathrm{Mn}_{0.13} \mathrm{O}_{2} @ \mathrm{~V}_{2} \mathrm{O}_{5}$ cathode material was also successfully synthesized by a wet-chemical method. In this material, the interior and exterior of the sphere particle were coated and penetrated with $\mathrm{V}_{2} \mathrm{O}_{5}$. Consequently, the $\mathrm{V}_{2} \mathrm{O}_{5}$-coated 
sample exhibited outstanding electrochemical performance.

\section{Experimental section}

The precursor of the material was synthesized by co-precipitation method. $\mathrm{NiSO}_{4} \cdot 6 \mathrm{H}_{2} \mathrm{O}$ and $\mathrm{CoSO}_{4} \cdot 7 \mathrm{H}_{2} \mathrm{O}$ with molar ratio of 0.9:0.1 were mixed in deionized water, marked as high-nickel solution; $\mathrm{NiSO}_{4} \cdot 6 \mathrm{H}_{2} \mathrm{O}$, $\mathrm{CoSO}_{4} \cdot 7 \mathrm{H}_{2} \mathrm{O}$ and $\mathrm{MnSO}_{4} \cdot \mathrm{H}_{2} \mathrm{O}$ with molar ratio of 0.7:0.1:0.2 were dissolved in deionized water, marked as low-nickel solution. The lownickel solution was gradually added to the high-nickel solution, and the high-nickel solution was pumped into the reactor at the same time. In the reaction process, $\mathrm{Ar}$ was used as a shielding gas and the reaction temperature was about $60{ }^{\circ} \mathrm{C}$. The $\mathrm{NaOH}$ solution and the $\mathrm{NH}_{3} \cdot \mathrm{H}_{2} \mathrm{O}$ solution were fed into the reactor separately. With constantly stirring, $\mathrm{Ni}_{0.9} \mathrm{Co}_{0.1}(\mathrm{OH})_{2}$ core was generated first and the precipitation continuously deposited on the core. In the last stage, $\mathrm{NaOH}$ solution was changed as $\mathrm{Na}_{2} \mathrm{CO}_{3}$ solution, so that metal carbonate shell grew on the surface of the precursor. So, the FCG precursor with core-shell structure was obtained. The precursor and $\mathrm{Li}_{2} \mathrm{CO}_{3}$ were mixed with a molar ratio of $1: 1.05$. The mixture was calcined under oxygen atmosphere at $450{ }^{\circ} \mathrm{C}$ for $5 \mathrm{~h}$ and then at $750{ }^{\circ} \mathrm{C}$ for $12 \mathrm{~h}$. In the end, core-shell structured FCG $\mathrm{LiNi}_{0.75} \mathrm{Co}_{0.12} \mathrm{Mn}_{0.13} \mathrm{O}_{2}$ cathode material was obtained as pristine material. The $\mathrm{V}_{2} \mathrm{O}_{5}$-coated $\mathrm{LiNi}_{0.75} \mathrm{Co}_{0.12} \mathrm{Mn}_{0.13} \mathrm{O}_{2}$ sample was prepared by a wet-chemical method. Vanadium(IV)-oxy acetylacetonate $\left(\mathrm{C}_{10} \mathrm{H}_{14} \mathrm{O}_{5} \mathrm{~V}\right)$ was dissolved in alcohol and mixed with pristine material. It was dispersed by ultrasonic treatment, and then heated until dried by stirring. After that, the powder was calcined in air at $500{ }^{\circ} \mathrm{C}$ for $6 \mathrm{~h}$. Finally, the $3 \mathrm{wt} \% \mathrm{~V}_{2} \mathrm{O}_{5}$-coated $\mathrm{LiNi}_{0.75} \mathrm{Co}_{0.12} \mathrm{Mn}_{0.13} \mathrm{O}_{2}$ material was obtained.

The crystalline phases of the pristine and $\mathrm{V}_{2} \mathrm{O}_{5}$-coated samples were identified with an X-ray powder diffraction (XRD, X'Pert Powder,
PANalytical, USA) equipped with $\mathrm{Cu}-\mathrm{K} \alpha$ radiation. The morphologies of these samples were observed by scanning electron microscopy (SEM, JSM-6360LV, JEOL, Japan). The microstructures of the samples were examined by using transmission electron microscopy (TEM, Tecnai G2 F20 S-TWIN, FEI, USA). The morphologies of the crosssection of the samples were observed by Focused Ion beam (FIB, HELIOS NanoLab 600i, FEI, USA). The element distributions of samples were characterized with an energy-dispersive X-ray spectrometer (EDS). The chemical valence states were analyzed by Xray photoelectron spectroscopy (XPS, Escalab 250Xi, Thermo Fisher Scientific, China).

The slurry was prepared by mixing prepared sample, carbon black (super P) and polyvinylidene fluoride in the weight ratio of 8:1:1. After that, the slurry was cast onto aluminum foil for drying in a vacuum oven. The CR2025 coin cell was fabricated in glove box. Metal lithium was used as the negative electrode. PE and PP composite films were used as separator, and $1 \mathrm{~mol} \cdot \mathrm{L}^{-1}$ lithium hexafluorophosphate dissolved in DMC: EC: EMC (volume ratio 1:1:1) was used as electrolyte. The electrochemical performances of the material were studied by an automatic galvanostatic charge-discharge unit, a LAND battery cycler (CT2001A, China), 2.5-4.3 V versus $\mathrm{Li} / \mathrm{Li}^{+}$electrode. The cyclic voltammetry (CV) curve was obtained by using an electrochemical workstation (CHI660D, China). The test voltage range was $2.5-4.3 \mathrm{~V}$ and the scanning speed was $0.1 \mathrm{mV} \mathrm{s}^{-1}$. Electrochemical impedance spectroscopy (EIS) was detected by the same workstation and the frequency range was from $0.01 \mathrm{~Hz}$ to $100 \mathrm{kHz}$.

\section{Results and discussion}

The schematic illustration of the preparation process is shown in Scheme 1. Firstly, the FCG precursor made of metal hydroxide was

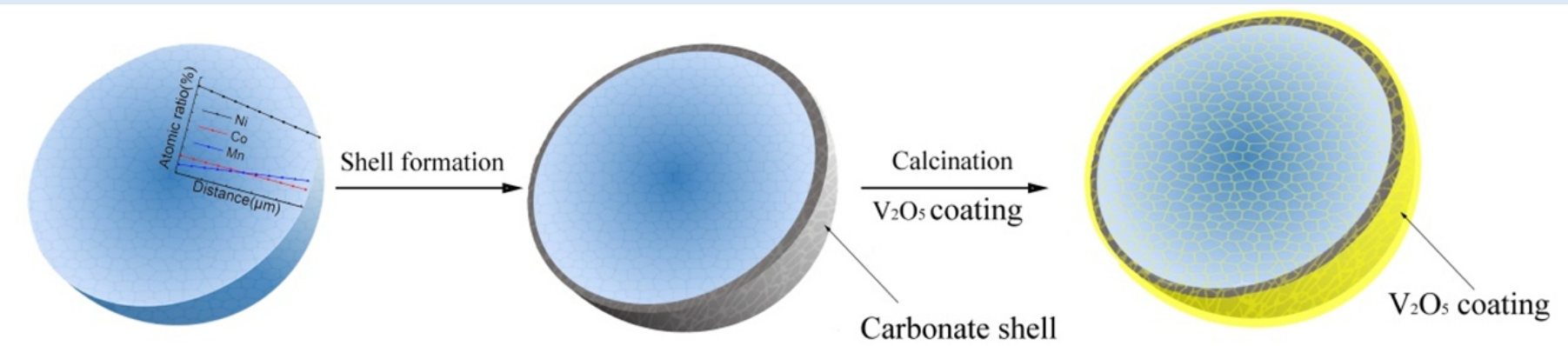

FCG precursor Core-shell structured FCG precursor $\mathrm{LiNi} 0.75 \mathrm{Co} 0.12 \mathrm{Mn}_{0.13} \mathrm{O}_{2} @ \mathrm{~V}_{2} \mathrm{O}_{5}$

Scheme 1 Schematic illustration of the preparation process of $\mathrm{LiNi}_{0.75} \mathrm{Co}_{0.12} \mathrm{Mn}_{0.13} \mathrm{O}_{2} @ \mathrm{~V}_{2} \mathrm{O}_{5}$ cathode material.
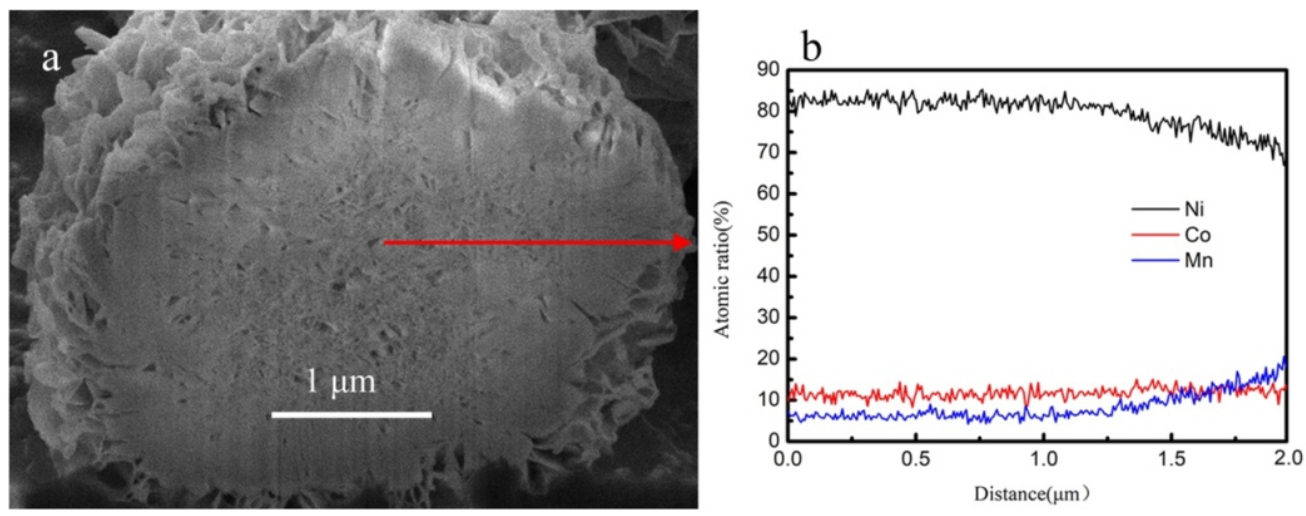

Fig. 1 (a) Cross-section SEM image of the precursor particle; (b) linear EDS spectrum of the particle section. 
prepared by co-precipitation method. Secondly, metal carbonate was deposited on the surface of metal hydroxide to form a thin shell, in which the concentration of Mn was high. Finally, after wet-chemical and calcination treatments, the surface of the sphere was coated by $\mathrm{V}_{2} \mathrm{O}_{5}$ layer, and the interior was penetrated by $\mathrm{V}_{2} \mathrm{O}_{5}$ particles.

The cross-section SEM image and the corresponding EDS spectrum of the precursor material are shown in Fig. 1. It can be seen from the cross-section SEM image (Fig. 1a) that there are many pores inside the particle. Such a structure is designed to provide physical channels for the lithium source and the coating material to penetrate into the interior of the precursor material. Figure $1 \mathrm{~b}$ shows the molar concentration variations along the red arrow. It can be observed that, from inner core to outer shell, the molar concentration of Ni element decreases slowly in the inner core and decreases fast in the outer shell; the molar concentration of Co element remains almost unchanged; and the molar concentration of $\mathrm{Mn}$ element increases slowly in the core, and increases fast in the shell. The reason for the molar concentrations of Ni element decreases fast and Mn element increases fast in the shell, is that $\mathrm{MnCO}_{3}$ deposits easier compared with $\mathrm{NiCO}_{3}$ in the coprecipitation process.

The crystalline structures of the pristine and $\mathrm{V}_{2} \mathrm{O}_{5}$-coated samples were investigated by XRD, as shown in Fig. 2. The two samples both

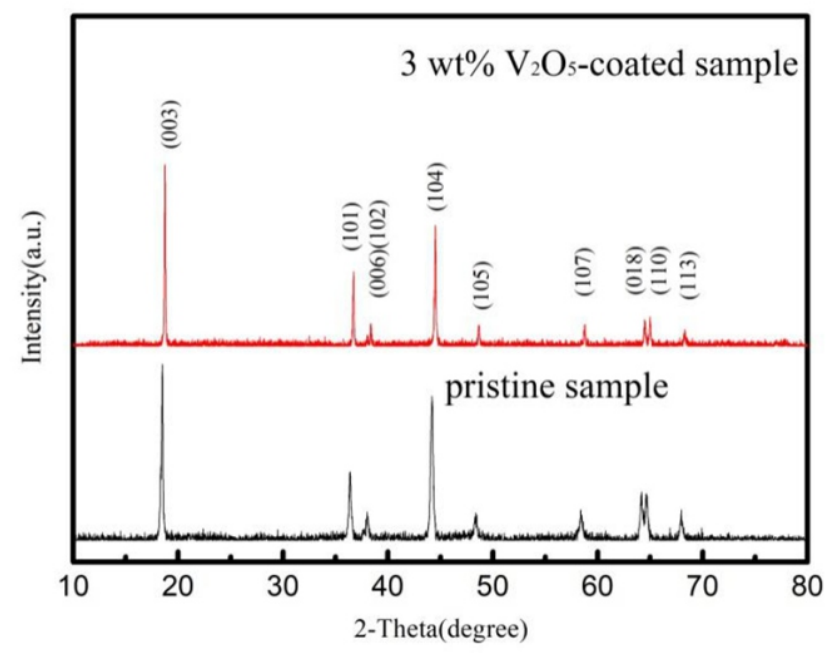

Fig. 2 XRD patterns of pristine and $\mathrm{V}_{2} \mathrm{O}_{5}$-coated samples. belong to the hexagonal $\alpha-\mathrm{NaFeO}_{2}$ structure, and no characteristic peaks of any impurities can be observed in the patterns. The characteristic peak of $\mathrm{V}_{2} \mathrm{O}_{5}$ was not observed in the XRD pattern of $\mathrm{V}_{2} \mathrm{O}_{5}$-coated sample. The possible reason is that the $\mathrm{V}_{2} \mathrm{O}_{5}$ was amorphous or the coating amount of $\mathrm{V}_{2} \mathrm{O}_{5}$ is too low to be detected. In the XRD patterns, $(006) /(102)$ and $(018) /(110)$ peaks were significantly split, which indicates that the layered structure of the material is $\operatorname{good}^{37}$. In addition, the lattice parameters of pristine and $\mathrm{V}_{2} \mathrm{O}_{5}$-coated samples were investigated and summarized in Table 1. It can be seen from the data, $a$ value has no obvious change before and after $\mathrm{V}_{2} \mathrm{O}_{5}$ coating; however, the $c$ value and the unit cell volume increase after $\mathrm{V}_{2} \mathrm{O}_{5}$ coating. It is suggested that vanadium element was doped into the crystal structure of the material. The increases of lattice parameter and unit cell volume are advantageous to the lithium ion transport, which could improve the electrochemical properties of the material. The ratios of $(003) /(104)$ of the samples were 1.32 (pristine sample) and $1.53\left(\mathrm{~V}_{2} \mathrm{O}_{5}\right.$-coated sample), respectively. Generally, the both ratios are greater than 1.2, indicating that the cathode materials possess good layered structures ${ }^{38}$.

Fig. 3 shows the typical SEM images and EDS spectra of the pristine and $\mathrm{V}_{2} \mathrm{O}_{5}$-coated samples. In Fig. 3a, it is seen that the particles of pristine sample were spherical or quasi-spherical, with an average particle size of about $5 \mu \mathrm{m}$. It can be seen from Fig. $3 \mathrm{~b}$ that the primary material particles were $100-300 \mathrm{~nm}$. After the $\mathrm{V}_{2} \mathrm{O}_{5}$ coating treatment, the morphology of the sample was not changed, as shown in Fig. $3 \mathrm{~d}$ and $3 \mathrm{e}$. There was no characteristic peak of $\mathrm{V}$ element in the pristine sample (Fig. 3c); however, the characteristic peak of $\mathrm{V}$ element can be observed in $\mathrm{V}_{2} \mathrm{O}_{5}$-coated sample (Fig. 3f), indicating the existence of $\mathrm{V}_{2} \mathrm{O}_{5}$ coating on the particle surface.

Table 1 Lattice parameters of pristine and $3 \mathrm{wt} \% \mathrm{~V}_{2} \mathrm{O}_{5}$-coated samples.

\begin{tabular}{ccccc}
\hline samples & $\mathrm{a}(\AA)$ & $\mathrm{c}(\AA)$ & Volume $\left(\AA^{3}\right)$ & $\mathrm{I}_{003} / \mathrm{I}_{104}$ \\
\hline pristine & 2.8918 & 13.7226 & 99.38 & 1.32 \\
& & & & \\
$\mathrm{~V}_{2} \mathrm{O}_{5}$-coated & 2.8856 & 14.2092 & 102.46 & 1.53 \\
\hline
\end{tabular}
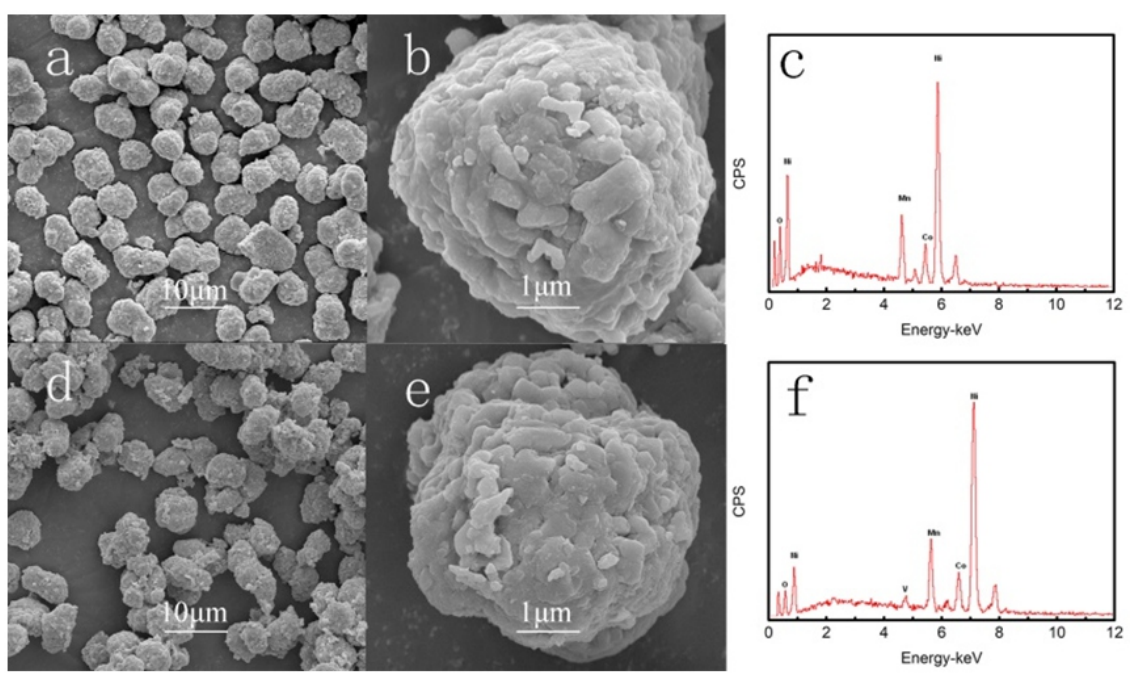

Fig. 3 (a, b) SEM images and (c) EDS spectrum of pristine sample; (d, e) SEM images and (f) EDS spectrum of $\mathrm{V}_{2} \mathrm{O}_{5}$-coated sample. 
TEM images of $\mathrm{V}_{2} \mathrm{O}_{5}$-coated sample were also investigated, as shown in Fig. 4. It can be clearly seen that a relatively uniform $\mathrm{V}_{2} \mathrm{O}_{5}$ coating layer on the surface of the particle, and the thickness is about 4 $\mathrm{nm}$. Fig. 5a shows the cross-section SEM image of $\mathrm{V}_{2} \mathrm{O}_{5}$-coated sample. It is found that there are fewer pores compared with those in the precursor. EDS spectrum of the corresponding cross-section part of the sample is shown in Fig. 5b. It is seen that V element is detected in the spectrum. The red arrow in Fig. 5a is the linear scanning direction of EDS spectrum. The distributions of $\mathrm{Ni}, \mathrm{Co}$ and $\mathrm{Mn}$ elements in the EDS spectrum are shown in Fig. 5c. It is found that the molar concentration of $\mathrm{Ni}$ element decreases slowly in the core and decreases fast in the shell, and the molar concentration of Mn element increases slowly in the core and increases fast in the shell, which is in line with the original material design of high-nickel core and high-manganese shell. Figs. 5d-g show the EDS mapping of the four elements, corresponding to the particle section in Fig. 5a. It can be seen that all the elements are evenly distributed in the particle. $\mathrm{V}$ element was also found on the section surface of the particle, which further indicates that $\mathrm{V}_{2} \mathrm{O}_{5}$ particles penetrate into the interior of the material.

The chemical valence states of the elements in pristine and $\mathrm{V}_{2} \mathrm{O}_{5-}$ coated samples were studied by XPS, as shown in Fig. 6. The XPS spectra of the samples are shown in Fig. 6(a). The V2p peak at 524.81 $\mathrm{eV}$ can be observed in Fig. 6(b), corresponding to the characteristic peak of $\mathrm{V}^{5+}$ ions in $\mathrm{V}_{2} \mathrm{O}_{5}^{39}$. This indicates that the coating on the surface of the pristine material is $\mathrm{V}_{2} \mathrm{O}_{5}$. Fig. 6(c) shows the oxygen peak of pristine sample before and after $\mathrm{V}_{2} \mathrm{O}_{5}$ coating. The oxygen peaks at

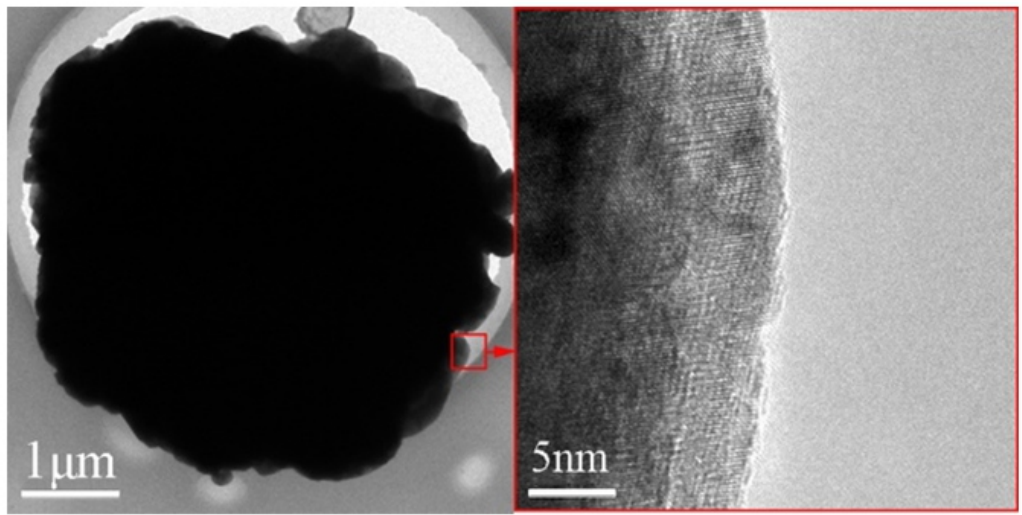

Fig. 4 Typical TEM images of $\mathrm{V}_{2} \mathrm{O}_{5}$-coated sample.
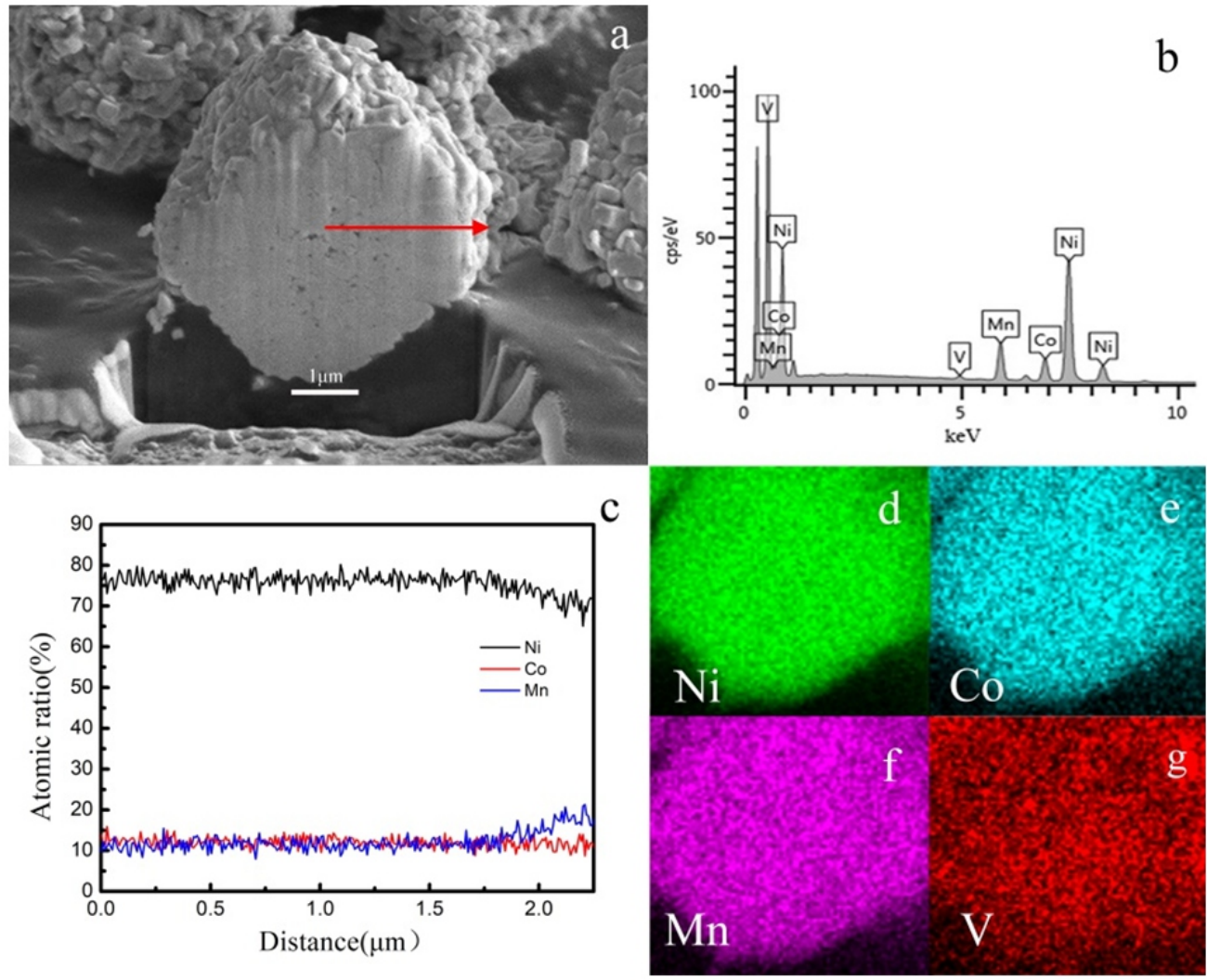

Fig. 5 (a) Cross-section SEM image of $\mathrm{V}_{2} \mathrm{O}_{5}$-coated sample particle; (b) EDS spectrum and (c) linear EDS spectrum of the particle section; EDS mappings of (d) $\mathrm{Ni}$, (e) $\mathrm{Co}$, (f) $\mathrm{Mn}$ and (g) $\mathrm{V}$ elements of the particle section. 
$531.24 \mathrm{eV}\left(\mathrm{V}_{2} \mathrm{O}_{5}\right.$-coated sample) and $531.29 \mathrm{eV}$ (pristine sample) correspond to the oxygen peak of layered ternary material; $529.41 \mathrm{eV}$ $\left(\mathrm{V}_{2} \mathrm{O}_{5}\right.$-coated sample) corresponds to the oxygen peak of $\mathrm{V}_{2} \mathrm{O}_{5}{ }^{40}$ In Fig. $6(\mathrm{~d}-\mathrm{f})$, the peaks of $\mathrm{Ni} 2 \mathrm{p}_{32}, \mathrm{Co} 2 \mathrm{p}_{3 / 2}$ and $\mathrm{Mn} 2 \mathrm{p}_{3 / 2}$ were observed at $854.42,780.14$ and $642.03 \mathrm{eV}$, respectively, corresponding to $\mathrm{Ni}^{2+}, \mathrm{Co}^{3+}$ and $\mathrm{Mn}^{4+}$ in the material, ${ }^{41}$ proving that the binding energies of the $\mathrm{V}_{2} \mathrm{O}_{5}$ coated sample are not changed by $\mathrm{V}_{2} \mathrm{O}_{5}$ coating.

The electrochemical properties of the samples were further investigated. Fig. 7 shows the first cycle charge-discharge profiles of pristine sample and $\mathrm{V}_{2} \mathrm{O}_{5}$-coated sample at the current density of $0.1 \mathrm{C}$. The initial discharge capacities of the pristine and $\mathrm{V}_{2} \mathrm{O}_{5}$-coated sample were 199.1 and $192.7 \mathrm{mAh} \mathrm{g}^{-1}$, respectively. It can be observed that the discharge capacity of $\mathrm{V}_{2} \mathrm{O}_{5}$-coated sample was a little lower than that of pristine sample, as $\mathrm{V}_{2} \mathrm{O}_{5}$ is inactive in the electrochemical reaction and has no contribution to the capacity. Fig. 8(a) shows the rate performances of the pristine and $\mathrm{V}_{2} \mathrm{O}_{5}$-coated samples. The discharge capacities of pristine and $\mathrm{V}_{2} \mathrm{O}_{5}$-coated samples achieved 138.6 and 144.2 $\mathrm{mAh} \mathrm{g}{ }^{-1}$ at $10 \mathrm{C}$, respectively. It is easily found that $\mathrm{V}_{2} \mathrm{O}_{5}$-coated sample exhibited higher discharge capacities especially at high rates $(2,5$ and $10 \mathrm{C}$ ). The cycling performances of the pristine and $\mathrm{V}_{2} \mathrm{O}_{5}$-coated samples were shown in Fig. 8(b). The batteries were charged and discharged for 100 cycles at the current density of $1 \mathrm{C}$. The discharge capacity of pristine sample was from $188.2 \mathrm{mAh} \mathrm{g}^{-1}$ at first cycle to $141.6 \mathrm{mAh} \mathrm{g}^{-1}$ at 100th cycle, with capacity retention of only $75.2 \%$. However, the discharge capacity of $\mathrm{V}_{2} \mathrm{O}_{5}$-coated sample was from 186.1 $\mathrm{mAh} \mathrm{g}^{-1}$ at first cycle to $160.9 \mathrm{mAh} \mathrm{g}^{-1}$ at 100th cycle, with the capacity retention of $86.5 \%$, which is much higher than that of pristine sample. The higher capacity retention of $\mathrm{V}_{2} \mathrm{O}_{5}$-coated sample is attributed to the
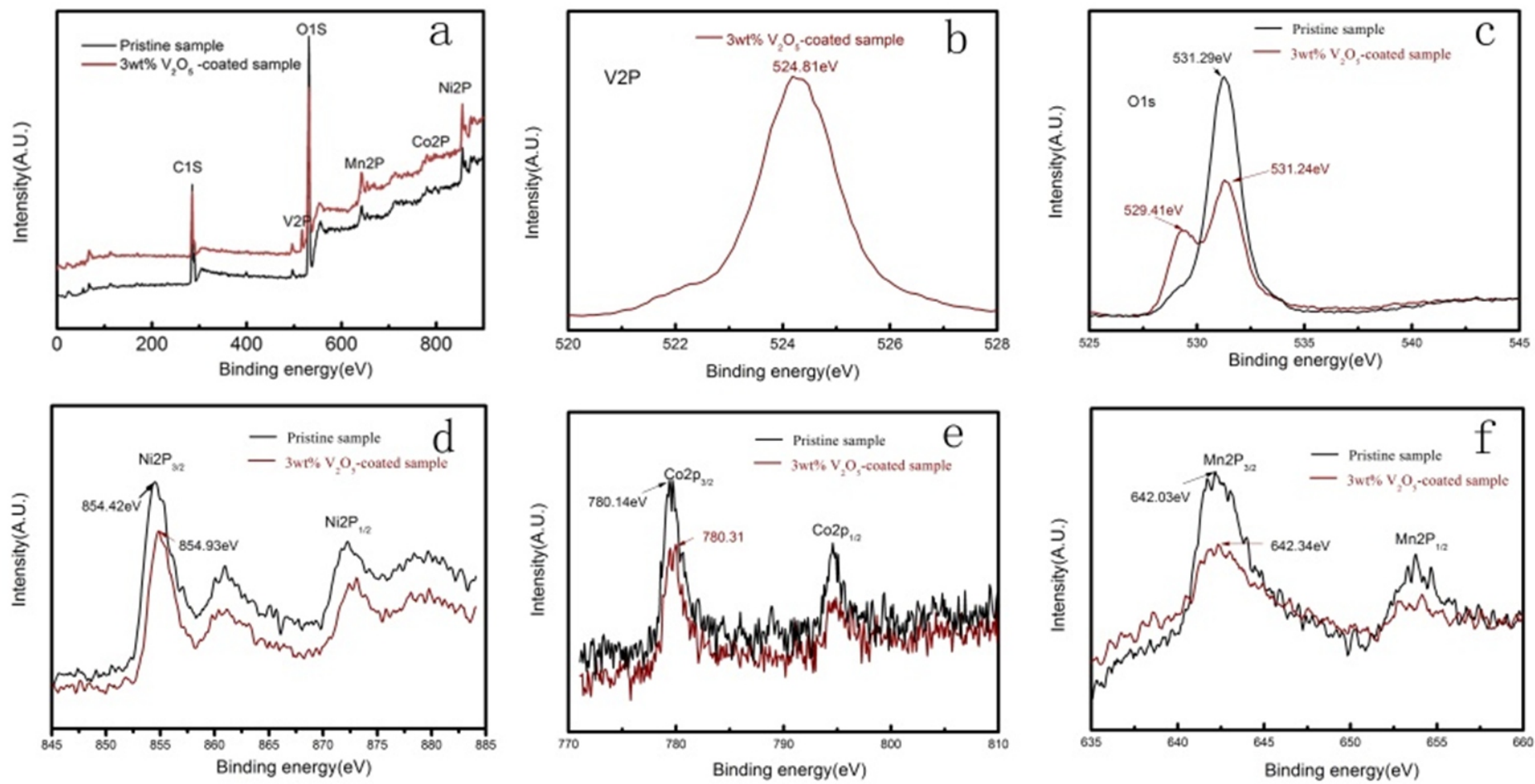

Fig. 6 XPS spectra of pristine and $\mathrm{V}_{2} \mathrm{O}_{5}$-coated samples.

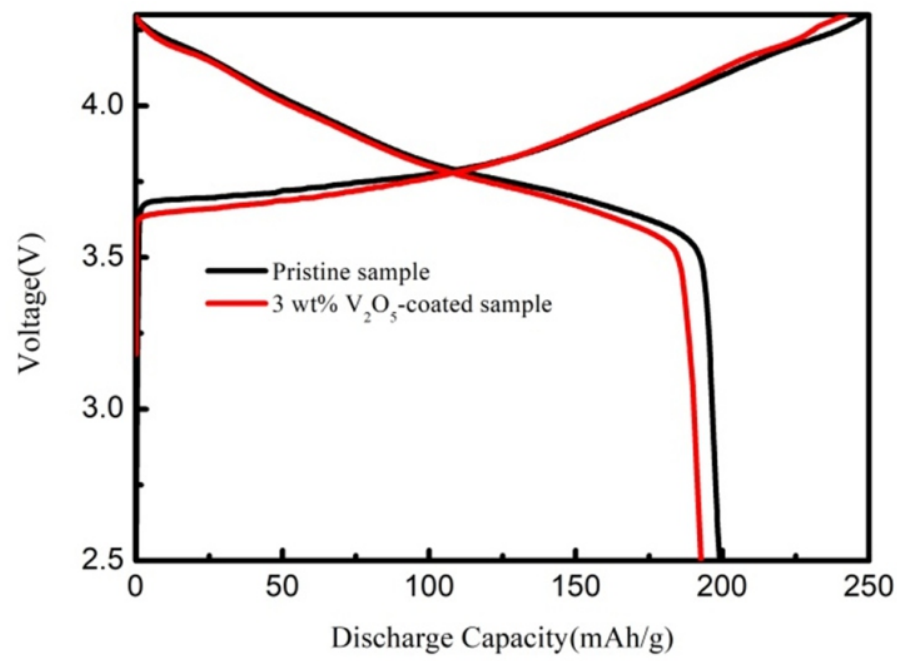

Fig. 7 The initial charge/discharge curves of pristine and $\mathrm{V}_{2} \mathrm{O}_{5}$-coated samples. 

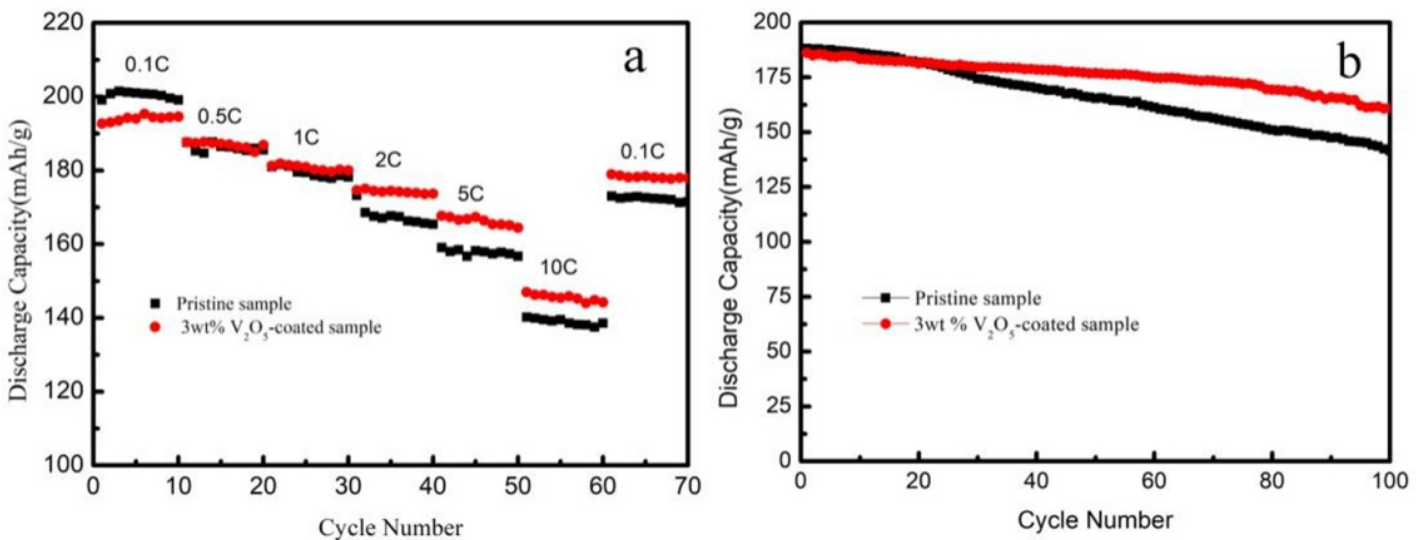

Fig. 8 (a) Rate performances and (b) cycling performances of pristine and $\mathrm{V}_{2} \mathrm{O}_{5}$-coated samples.
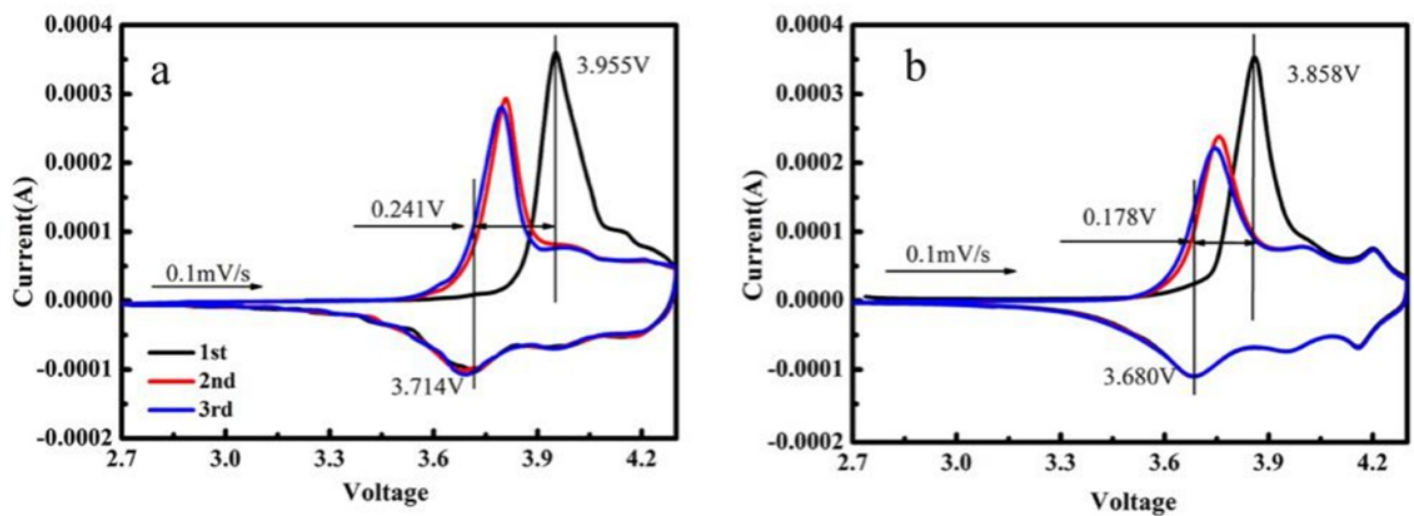

Fig. $9 \mathrm{CV}$ curves of (a) pristine and (b) $\mathrm{V}_{2} \mathrm{O}_{5}$-coated samples.

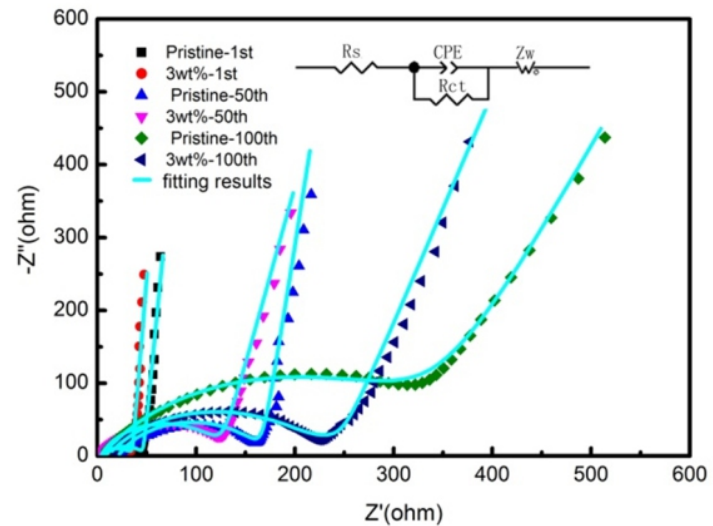

Fig. 10 EIS of pristine and $\mathrm{V}_{2} \mathrm{O}_{5}$-coated samples after different number of cycles

Table 2 Parameters of the samples obtained from equivalent circuit fitting after different number of cycles.

\begin{tabular}{lllll}
\hline Samples & Cycles & $\mathrm{R}_{\mathrm{s}}(\Omega)$ & $\mathrm{R}_{\mathrm{ct}}(\Omega)$ & $\mathrm{D}_{\mathrm{Li}+}\left(\mathrm{cm}^{2} \mathrm{~S}^{-1}\right)$ \\
\hline Pristine & 0 & 5.02 & 44.64 & $1.13 \times 10^{-11}$ \\
& 50 th & 8.62 & 159.5 & $4.93 \times 10^{-12}$ \\
& 100 th & 13.17 & 321.85 & $1.97 \times 10^{-12}$ \\
& 0 & 3.6 & 27.58 & $2.15 \times 10^{-11}$ \\
$\mathrm{~V}_{2} \mathrm{O}_{5}$-coated & 50 th & 4.68 & 120.6 & $7.02 \times 10^{-12}$ \\
& 100 th & 10.42 & 228.27 & $5.48 \times 10^{-12}$ \\
\hline
\end{tabular}


coating and penetration of $\mathrm{V}_{2} \mathrm{O}_{5}$, which inhibits the damage of the structure and side reactions.

Fig. 9 shows the $\mathrm{CV}$ curves of pristine and $\mathrm{V}_{2} \mathrm{O}_{5}$-coated samples, with the scanning speed of $0.1 \mathrm{mV} \mathrm{s}^{-1}$. A pair of redox peaks was in the range of 3.6-4.0 V. The first cycle showed only one obvious oxidation peak, corresponding to the conversion from $\mathrm{Ni}^{2+}$ to $\mathrm{Ni}^{4+}$. From the main redox peak, it can be inferred that the deintercalation and intercalation of lithium ions mainly correspond to the transition between $\mathrm{Ni}^{2+}$ and $\mathrm{Ni}^{4+}$. The pristine sample had an oxidation peak of $3.955 \mathrm{~V}$, which is the potential of delithiation; and a reduction peak of $3.714 \mathrm{~V}$, which is the potential of lithiation, while $\mathrm{V}_{2} \mathrm{O}_{5}$-coated sample had oxidation and reduction potentials of 3.858 and $3.680 \mathrm{~V}$, respectively. The potential difference $(0.178 \mathrm{~V})$ of $\mathrm{V}_{2} \mathrm{O}_{5}$-coated sample was smaller than that of pristine sample $(0.241 \mathrm{~V})$, which indicates that $\mathrm{V}_{2} \mathrm{O}_{5}$ coating can inhibit the interfacial polarization of the gradient material.

To further understand the electron/ion transfer characteristics of the two samples, EIS measurement was carried out, in which the pristine and $\mathrm{V}_{2} \mathrm{O}_{5}$-coated samples were discharged to $2.5 \mathrm{~V}$ after several cycles at $1 \mathrm{C}$ rate. The EIS was tested and the Nyquist plots and their fitting curves were obtained as shown in Fig. 10. It can be observed that the fitting patterns of the samples were composed of two parts: a semicircle in the high frequency region and a straight line in the low frequency region. $\mathrm{R}_{\mathrm{s}}$ represents the ohmic resistance between the electrolyte and the electrode in the battery, which is the intercept impedance on the $Z^{\prime}$-axis. $R_{c t}$ represents the interfacial charge transfer resistance of the material, and $Z_{w}$ is Warburg impedance. The values of $\mathrm{R}_{\mathrm{s}}$ and $\mathrm{R}_{\mathrm{ct}}$ obtained through Zview software are shown in Table 2. The $R_{s}$ of the two samples were lower than $R_{c t}$, and lower than $15 \Omega$. The $R_{s}$ of $\mathrm{V}_{2} \mathrm{O}_{5}$-coated sample was lower compared with pristine sample. The $R_{s}$ and $R_{c t}$ both increased with increasing numbers of cycles. After 100 cycles, the $\mathrm{R}_{\mathrm{ct}}$ value of pristine sample increased from 44.64 to 321.85 $\Omega$, and the $\mathrm{R}_{\mathrm{s}}$ value of $\mathrm{V}_{2} \mathrm{O}_{5}$-coated sample increased from 27.58 to $228.27 \Omega$. It is apparent that the $\mathrm{R}_{\mathrm{ct}}$ values of $\mathrm{V}_{2} \mathrm{O}_{5}$-coated sample were lower at different numbers of cycles, which illustrate that the coating can effectively inhibit the adverse chemical reactions between electrolyte and electrode material and reduce the impedance. The diffusion coefficient of lithium ions $\left(\mathrm{D}_{\mathrm{Li}}{ }^{+}\right)$of the two samples at different cycles were calculated ${ }^{41,42}$ and the results are summarized in Table 2. It can be observed that $\mathrm{D}_{\mathrm{Li}}{ }^{+}$of the two samples decreased with the increase in cycle numbers, as the structures of the samples were gradually destroyed and the transport channels of lithium ions were reduced during the cycling process; and $\mathrm{D}_{\mathrm{Li}}{ }^{+}$of pristine sample was lower than $\mathrm{V}_{2} \mathrm{O}_{5}$-coated sample at different cycle numbers, the reason is that the structure damage and side reactions are inhibited by $\mathrm{V}_{2} \mathrm{O}_{5}$ coating, and vanadium element doping is beneficial for lithium ion diffusion. After 100 cycles, $\mathrm{D}_{\mathrm{Li}}^{+}$values of pristine and $\mathrm{V}_{2} \mathrm{O}_{5}$-coated samples were $1.97 \times 10^{-12}$ and $5.48 \times 10^{-12} \mathrm{~cm}^{2} \mathrm{~S}^{-1}$, respectively. It is proved that $\mathrm{V}_{2} \mathrm{O}_{5}$ coating can increase the ionic conductivity of the material and thus improve the electrochemical properties.

\section{Conclusions}

A core-shell structured FCG cathode material LiNi $\mathrm{Lin}_{0.7} \mathrm{Co}_{0.12} \mathrm{Mn}_{0.13} \mathrm{O}_{2} @ \mathrm{~V}_{2} \mathrm{O}_{5}$ was successfully prepared. Compared with the pristine sample, $\mathrm{V}_{2} \mathrm{O}_{5^{-}}$ coated sample showed significant enhancements in cycling and rate performances. After cycled at $1 \mathrm{C}$ rate for 100 cycles, the capacity retention of $\mathrm{V}_{2} \mathrm{O}_{5}$-coated sample was $86.5 \%$, which is much higher than that of pristine sample, $75.2 \% . \mathrm{V}_{2} \mathrm{O}_{5}$-coated sample reached a higher capacity of $144.2 \mathrm{mAh} \mathrm{g}^{-1}$ at $10 \mathrm{C}$ rate compared with that of pristine sample, $138.6 \mathrm{mAh} \mathrm{g}^{-1}$. The results show that $\mathrm{V}_{2} \mathrm{O}_{5}$ was not only coated on the surface of the material, but also penetrated into the interior of the material. The structural damage could be inhibited by $\mathrm{V}_{2} \mathrm{O}_{5}$ coating during the charge and discharge process. In addition, $\mathrm{R}_{\mathrm{s}}$ and $\mathrm{R}_{\mathrm{ct}}$ decreased, and $\mathrm{D}_{\mathrm{Li}}^{+}$increased through $\mathrm{V}_{2} \mathrm{O}_{5}$ coating. Furthermore, a small amount of $\mathrm{V}$ element was doped into the crystal lattices of the material, which is also beneficial for the transport of lithium ions. Thus, the electrochemical performance of the cathode material was significantly improved. This ternary material with novel structure could be considered as a promising high-energy cathode material in LIBs.

\section{Conflict of interest}

There are no conflicts to declare.

\section{Acknowledgements}

This work was supported by the National Natural Science Foundation of China (grant Nos. 51502350, 51772334, and 51702367), China Postdoctoral Science Foundation (grant No. 2016M592447), and International Postdoctoral Exchange Fellowship Program (grant No. 155212).

\section{References}

1. F. Mushtaq, R. Mat and F. N. Ani, Renew. Sust. Energ. Rev., 2014, 39, 555574.

2. H. Chen, B. Zhang, X. Wang, P. Dong, H. Tong, J. C. Zheng, W. Yu and J. Zhang, ACS App. Mater. Inter., 2018, 10, 3590-3595.

3. R. Xiao, L. Gao, Z. Wei, R. Spinney, S. Luo, D. Wang, D. D. Dionysiou, C. J. Tang and W. Yang, Environ. Pollut., 2017, 231, 1446-1452.

4. H. Chen, Y. Huang, G. Mao, H. Tong, W. Yu, J. Zheng and Z. Ding, Front. Chem., 2018, 6, 174

5. B. He, J. Wang, Y. Q. Fan, Y. L. Jiang, Y. J. Zhai, Y. Wang, Q. S. Huang, F. Dang, Z. D. Zhang and N. Wang, J. Mater. Chem. A, 2018, 6, 19075-19084.

6. B. Xiao, W. H. Zhang, H. F. Xia, Z. T. Wang, L. B. Tang, C. S. An, Z. J. He, H. Tong and J. C. Zheng, Mater. Chem. Front., 2019, 3, 456-463.

7. B. Dunn, H. Kamath and J. M. Tarascon, Science, 2011, 334, 928-935.

8. H. Li, B. Zhang, Q. J. Zhou, J. Zhang, W. J. Yu, Z. Y. Ding, M. A. Tsiamtsouri, J. C. Zheng and H. Tong, Ceram. Int., 2019, 45, 7830-7838.

9. B. Zhang, H. Chen, H. Tong, X. Wang, J. Zheng, W. Yu, J. Zhang, J. Li and W. Zhang, J. Alloy. Compd., 2017, 728, 976-983.

10. M. M. Thackeray, C. Wolverton and E. D. Isaacs, Energy Environ. Sci., 2012, 5, 7854-7863.

11. A. K. Padhi, K. S. Nanjundaswamy and J. B. Goodenough, J. Electrochem. Soc., 1997, 144, 1188-1194.

12. G.V . Zhuang, G. Chen, J. Shim, X. Song, P. N. Ross and T. J. Richardson, J Power Sources, 2004, 134, 293-297.

13. P. Y. Hou, L. Q. Zhang and X. P. Gao, J. Mater. Chem. A, 2014, 2, 1713017138 .

14. S. W. Song, G. V. Zhuang and P. N. Ross Jr., J. Electrochem. Soc., 2003, 151, A1162-A1167.

15. Y. K. Sun, S. T. Myung, M. H. Kim, J. Prakash and K. Amine, J. Am. Chem. Soc., 2005, 127, 13411-13418.

16. H. J. Noh, Z. Chen, C. S. Yoon, J. Lu, K. Amine and Y. K. Sun, Chem Mater, 2013, 25, 2109-2115.

17. Y. K. Sun, S. T. Myung, B. C. Park, J. Prakash, I. Belharouak and K. Amine, Nat. Mater, 2009, 8, 320-324.

18. Y. K. Sun, B. R. Lee, H. J. Noh, H. Wu, S. T. Myung and K. Amine, $J$. Mater. Chem., 2011, 21, 10108-10112.

19. E. J. Lee, H. J. Noh, C. S. Yoon, Y. K. Sun, J. Power Sources, 2015, 273, 663-669.

20. J. W. Ju, E. J. Lee, C. S. Yoon, S. T. Myung and Y. K. Sun, J. Phys. Chem.C, 2013, 118, 175-182.

21. H. Kim, M. G. Kim, H. Y. Jeong, H. Nam and J. Cho, Nano Lett., 2015, 15, 2111-2119.

22. J. C. Zheng, Z. Yang, Z. J. He, H. Tong, W. J. Yu and J. F. Zhang, Nano Energy, 2018, 53, 613-621.

23. C. X. Hou, Z. X. Tai, L. L. Zhao, Y. J. Zhai, Y. Hou, Y. Q. Fan, F. Dang, J. 
Wang and H. K. Liu, J. Mater. Chem. A, 2018, 6, 9723-9736.

24. J. Chen, L. Li, L. Wu, Q. Yao, H. Yang, Z. Liu, L. Xia, Z. Chen, J. Duan and S. Zhong, J.Power Sources, 2018, 406, 110-117.

25. C. X. Hou, Y. Hou, Y. Q. Fan, Y. J. Zhai, Y. Wang, Z. Y. Sun, R. H. Fan, F. Dang and J. Wang, J. Mater. Chem. A, 2018, 6, 6967-6976.

26. H. Chen, B. Zhang, Y. Cao, X. Wang, Y. Yao, W. Yu, J. Zheng, J. Zhang and H. Tong, Ceram. Int., 2018, 44, 13706-13711.

27. K. Araki, N. Taguchi, H. Sakaebe, K. Tatsumi and Z. Ogumi, J. Power Sources, 2014, 269, 236-243.

28. J. Li, M. Fan, X. He, R. Zhao, C. Jiange and C. Wan, Ionics, 2006, 12(3), 215-218.

29. J. Cho, H. Kim and B. Park, J. Electrochem. Soc., 2004, 151, A1707-A1711.

30. H. Wang, A. D. Tang, K. L. Huang, S. Q. Liu, T. Nonferr. Metal. Soc., 2010, 20, $803-808$

31. S. K. Hu, G. H. Cheng, M. Y. Cheng, B. J. Hwang and R. Santhanam, J. Power Sources, 2009, 188, 564-569.

32. H. S. Kim, Y. Kim, S. I. Kim and S. W. Martin, J. Power Sources, 2006, 161, 623-627.

33. E. Potiron, A. L. G. L. Salle, A. Verbaere, Y. Piffard and D.Guyomard,
Electrochim. Acta, 1999, 45, 197-214.

34. J. W. Lee, S. M. Park and H. J. Kim, J. Power Sources, 2009, 188, 583587.

35. J. Cho, J.Mater. Chem., 2008, 18, 2257-2261.

36. X. Xiong, Z. Wang, H. Guo, Q. Zhang and X. Li, J. Mater. Chem. A, 2013, 1, 1284-1288

37. D. Li, T. Muta, L. Q. Zhang, M. Yoshio and H. Noguchi, J. Power Sources, 2004, 132, 150-155.

38. W. S. Yoon, K. Y. Chung, J. McBreen and X. Q. Yang, Electrochem. Commun., 2006, 8, 1257-1262.

39. J. L. G. Fierro, L. A. Arrua, J. M. Lopez Nieto and G. Kremenic, Appl. Catal., 1988, 37, 323-338.

40. G. A. Sawatzky and D. Post, Phys. Rev. B, 1979, 20(4), 1546-1555.

41. H. Tong, P. Dong, J. Zhang, J. Zheng, W. Yu, K. Wei, B. Zhang, Z. Liu and D. Chu, J. Alloy. Compd., 2018, 764, 44-50.

42. B. Zhang, P. Dong, H. Tong, Y. Yao, J. Zheng, W. Yu, J. Zhang and D. Chu, J. Alloy. Compd., 2017, 706, 198-204.

Publisher's Note Engineered Science Publisher remains neutral with regard to jurisdictional claims in published maps and institutional affiliations. 